UDK: 621.313

DOI: https://doi.org/10.24867/15BE29Stojanovic

\title{
MODELI TRANSFORMATORA I ASINHRONIH MAŠINA UZ UVAŽAVANJE VIŠIH HARMONIKA
}

\section{MODELING OF TRANSFORMERS AND INDUCTION MACHINES WITH REGARD OF HIGHER HARMONICS}

\section{Marko Stojanović, Marko Vekić, Fakultet tehničkih nauka, Novi Sad}

\section{Oblast - ENERGETIKA}

Kratak sadržaj - Ovaj rad bavi se modelovanjem odziva asinhronih mašina $i$ transformatora $u$ uslovima izobličenog mrežnog napona. Razmatrane su veličine kao što su gubici i električni moment.

Ključne reči: transformatori, asinhroni motori, viši harmonici

Abstract - This paper deals with the operation of Induction motors and transformers under distorted grid conditions.

Keywords: Induction motor, transformer, higher harmonics.

\section{UVOD - HARMONICI I KVALITET ELEKTRIČNE ENERGIJE}

Nelinearni potrošači, odnosno transformatori, rotirajuće obrtne električne mašine, FACTS uređaji, i komponente energetske elektronike su neki od uzroka pojave nesinusnih talasnih oblika struje i napona, što uzrokuje loš kvalitet električne energije.

Glavne posledice viših harmonika su neispravan rad upravljačkih uređaja, telefonske smetnje, dodatni gubici na vodovima (pri osnovnom i višim harmonicima), smanjen životni vek i uvećani gubici uređaja (npr. transformatori, obrtne mašine, i kondenzatorske baterije), i neispravan rad korisničkih uređaja.

Loš kvalitet električne energije ima mnoge štetne posledice na uređaje sistema i krajnje potrošače. Ono što čini ovu pojavu dodatno lošom je to što njeni efekti ostaju neopaženi sve dok ne dođe do kvara. Postoje mnogi standardi i srodna dokumenta koja se bave problemima kvaliteta električne energije. Lista dostupnih dokumenata o problemima kvaliteta omogućava lakšu potragu za potrebnim informacijama.

\section{MODEL ASINHRONE MAŠINE U SLUČAJU IZOBLIČENJA NAPONA NAPAJANJA}

Za struju i obrtni moment h-tog harmonika, na osnovu aproksimacija i Tevenenove predstave (slika 2.1), dobija se:

\section{NAPOMENA:}

Ovaj rad proistekao je iz master rada čiji mentor je bio dr Marko Vekić, vanr. prof.

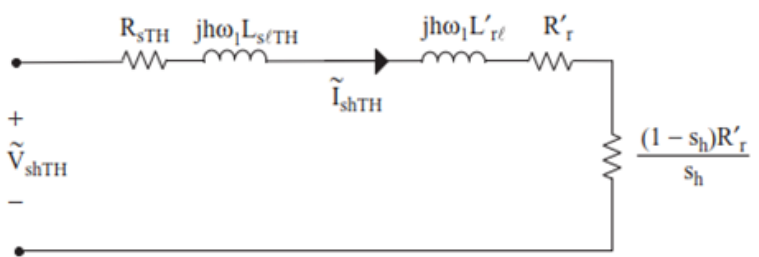

Slika 2.1 Tevenenovo ekvivalentno električno kolo asinhrone mašine za h-ti harmonik

$$
\begin{gathered}
\tilde{I}_{\text {shTH }}=\frac{\tilde{V}_{\text {shTH }}}{\left(R_{\text {shTH }}+\frac{R_{r}^{\prime}}{S_{h}}\right)+j h w_{1}\left(L_{s l T H}+L_{r l}^{\prime}\right)} \#(2.1) \\
T_{e h}=\frac{1}{w_{s h}} \frac{q_{1} V_{s h T H}^{2} \frac{R_{r}^{\prime}}{S_{h}}}{\left(R_{S T H}+\frac{R_{r}^{\prime}}{S_{h}}\right)^{2}+\left(h w_{1}\right)^{2}\left(L_{s l T H}+L_{r l}^{\prime}\right)^{2}} \#(2.2)
\end{gathered}
$$

slično, za obrtni moment usled osnovnog harmonika dobija se:

$$
T_{e 1}=\frac{1}{w_{s 1}} \frac{q_{1} V_{s 1 T H}^{2} \frac{R_{r}^{\prime}}{S_{1}}}{\left(R_{s T H}+\frac{R_{r}^{\prime}}{s_{1}}\right)^{2}+\left(w_{1}\right)^{2}\left(L_{s l T H}+L_{r l}^{\prime}\right)^{2}} \#(2.3)
$$

Klizanje asinhrone mašine pri prvom, kao i pri višim harmonicima, dato je sledećim relacijama:

$$
\begin{aligned}
s_{1} & =\frac{w_{s 1}-w_{m}}{w_{s 1}} \#(2.4) \\
s_{h} & =\frac{h w_{s 1}-w_{m}}{h w_{s 1}} \#(2.5)
\end{aligned}
$$

gde $w_{s 1}=\frac{w_{1}}{p / 2}$ predstavlja mehaničku sinhronu ugaonu brzinu osnovnog harmonika, a $w_{m}$ je mehanička ugaona brzina rotora.

Da bismo usvojili smer rotacije harmonijskih magnetopobudnih sila, u nastavku pretpostavljamo da prvi rotira $\mathrm{u}$ smeru kazaljke na satu (negativan matematički smer), peti obrnuto od smeta kazaljke na satu (pozitivan matematički smer), i sedmi, kao i prvi, u negativnom smeru. 


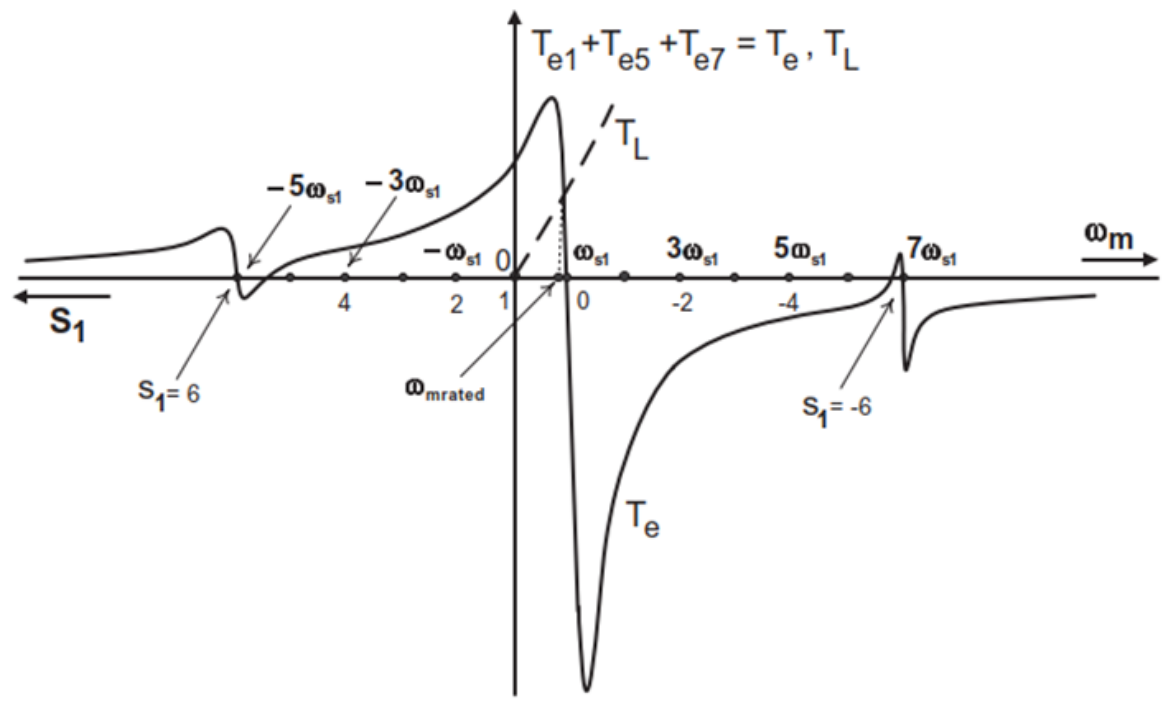

Slika 2.2 Obrtni moment asinhrone mašine za osnovni, peti i sedmi harmonik u funkciji ugaone brzine i klizanja osnovnog harmonika $s_{1}$

Superpozicija osnovnog $(h=1)$, petog $(h=5)$, i sedmog harmonika $(h=7)$ obrtnog momenta $T_{e}=T_{e 1}+T_{e 5}+T_{e 7}$ prikazana je na slici 2.2. U tački $w_{m}=w_{\text {mrated }}$ ukupni električni obrtni moment $T_{e}$ je jednak obrtnom momentu opterećenja $T_{L}$, odnosno $T_{e 1}+T_{e 5}+T_{e 7}=T_{L}$, gde $T_{e 1} \mathrm{i}$ $T_{e 7}$ predstavljaju motorske obrtne momente, a $T_{e 5}$ kočioni obrtni moment.

\section{SMANJIVANJE SNAGE TRANSFORMATORA USLED POJAVE VIŠIH HARMONIKA}

Poznato je da mora doći do smanjenja snage transformatora kada se vrši napajanje nelinearnih opterećenja. Jedna od metoda koja omogućava opterećenje višim harmonicima je projektovanje transformatora s tzv. Ksačiniocem (faktorom), koji predstavlja meru uticaja viših harmonika u struji opterećenja na transformator.

Gubici opterećenja transformatora u uslovima viših harmonika su:

$$
P_{L L}=\sum_{h=1}^{h \max } I_{h}^{2}+\left(\sum_{h=1}^{h \max } I_{h}^{2} h^{2}\right) P_{E C-R} \#(3.1)
$$

Prvi i drugi sabirak sa desne strane iz prethodne jednačine predstavljaju $I^{2} R$, i gubitke usled vrtložnih struja, redom. Ukoliko usvojimo da je $P_{L L}=P_{L L-R}$ važi:

$$
1+P_{E C-R}=\sum_{h=1}^{h \max } I_{h}^{2}+\left(\sum_{h=1}^{h \max } I_{h}^{2} h^{2}\right) P_{E C-R} \#
$$

ukoliko uvedemo K-sačinilac kao:

onda važi:

$$
K=\frac{\sum_{h=1}^{h \max } I_{h}^{2} h^{2}}{I_{R}^{2}} \#(3.3)
$$

$1+P_{E C-R}=\sum_{h=1}^{h \max } I_{h}^{2}+K\left(\frac{\sum_{h=1}^{h \max } I_{h}^{2}}{\sum_{h=1}^{h \max } I_{h}^{2}}\right) P_{E C-R}$

$$
\sum_{h=1}^{h \max } I_{h}^{2}=\frac{1+P_{E C-R}}{1+K \frac{I_{R}^{2}}{\sum_{h=1}^{h \max } I_{h}^{2}}\left(P_{E C-R}\right)}
$$

Dakle, kvadratni koren maksimalne vrednosti struje opterećenja koju transformator može da isporuči je:

$$
I_{\max }^{j}=\sqrt{\frac{1+P_{E C-R}}{1+K \frac{I_{R}^{2}}{\sum_{h=1}^{h \max } I_{h}^{2}}\left(P_{E C-R}\right)}}
$$

Koristeći $\mathrm{K}$ faktor i informacije o parametrima transformatora, kvadratni koren maksimalne dozvoljene vrednosti struje transformatora može se definisati i na sledeći način:

$$
=\sqrt{\frac{R_{D C}+\left(R_{E C-R}\right)(1-K)-\frac{\left(\Delta P_{f e}+\Delta P_{O S L}\right)}{I_{R}^{2}}}{R_{D C}}}
$$

gde: $R_{D C}=R_{D C \text { primarno }}+R_{D C s e k u n d a r n o}^{\prime}$ je ukupni DC otpor namotaja transformatora. $R_{E C-R}$ je pretpostavljeni dodatni otpor usled vrtložnih struja. Dalje:

$$
\begin{aligned}
& \Delta P_{f e}=\sum_{h=1}^{h \max } P_{f e h}-P_{f e R}, \\
& \Delta P_{O S L}=\sum_{h=1}^{h \max } P_{O S L h}-P_{O S L R} .
\end{aligned}
$$

$\Delta P_{f e}$ je razlika između ukupnih gubataka u gvožđu (uključujući harmonike) i procenjenih gubitaka u gvožđu bez harmonika. $\Delta P_{O S L}$ je razlika između ukupnih preostalih gubitaka (uključujući harmonike) i procenjenih ostalih gubitaka bez harmonika.

Smanjenje prividne snage (RAPR) je:

$$
R A P R=1-\left(V_{2 r m s}^{\text {nelinerno }} / V_{2 r m s}^{\text {rat }}\right) I_{\max }^{j}
$$

Rešavajaći po: $\sum_{h}^{h} \max I_{h}^{2}$, 


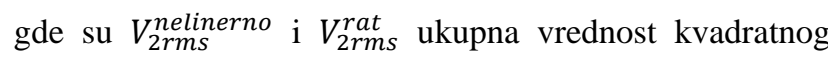
korena napona sekundara transformatora uključujući harmonike, i pretpostavljena vrednost kvadratnog korena sekundarnog namotaja bez harmonika, redom.

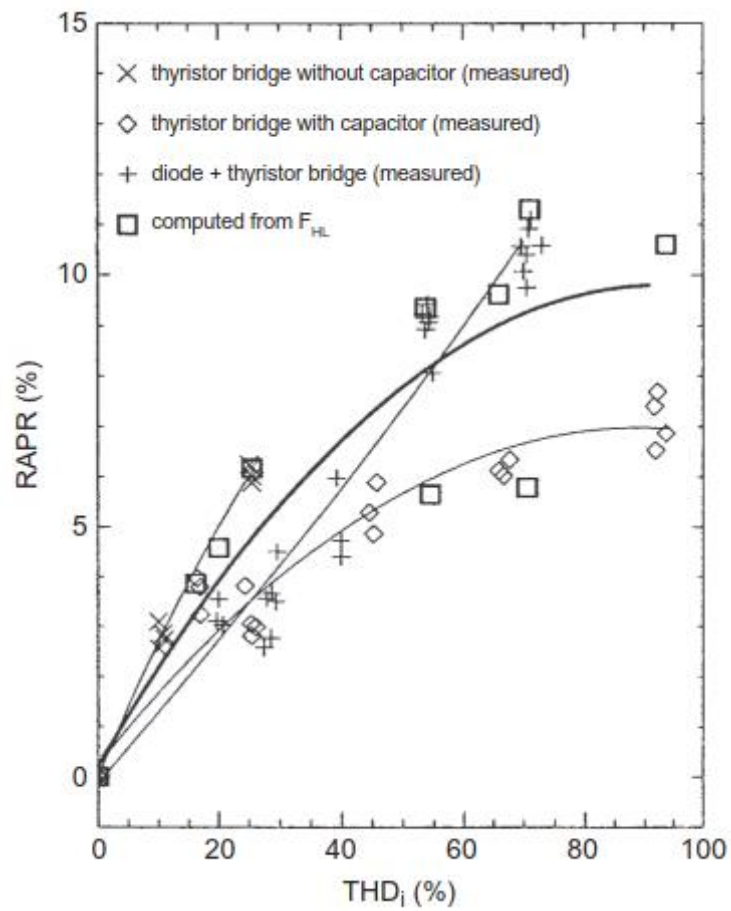

Slika 3.1 Izmereno smanjenje opsega prividne snage $(R A P R)$ jednofaznog transformatora snage 25kVA u funkciji ukupnog harmonijskog izobličenja struje $\left(T H D_{i}\right)$, gde su treći i peti harmonik izraziti.

\section{ZAKLJUČAK}

Cilj ovog rada bio je izvršiti pregled i analizu modela transformatora $\mathrm{i}$ asinhronih mašina $\mathrm{u}$ harmonijskom okruženju. Izbor je pao na ova dva uređaja jer su transformatori izuzetno bitan element sistema, a asinhroni motor elektromotornih pogona, i kao takvi u značajnoj meri utiču na kvalitet.

U radu su dati analitički izrazi i proračuni dejstva navedenih uređaja u uslovima poremećaja koji dolaze iz električne mreže, ali dat je i osvrt na njihovu osobinu da unose više harmonike, pre svega usled nelinearnih pojava u njihovom magnetnom jezgru.

\section{LITERATURA}

[1] Stoffel, T.; Andreas, A. (2008). Sun Spot One (SS1): San Luis Valley, Colorado (Data). NREL Report No. DA-5500-56507. http://dx.doi.org/10.5439/1052452 Accessed May 8, 2015.This image has been reprinted with permission from the National Renewable Energy Laboratory.

[2] Allen E, Kosterev DN, Pourbeik P. Validation of power system models. In: 2010 IEEE Power and Energy Society general meeting, Minneapolis, MN. doi:10.1109/PES.2010.5589874.

[3] Miller NW, Sanchez Gasca JJ, Price WP, Delmerico RW. Dynamic modeling of GE 1.5 and 3.6 MW wind turbine-generators for stability simulations, 0-78037989-6/03@2003 IEEE.

[4] Wang Q, Chang L. An intelligent maximum power extraction algorithm for inverter-based variable speed wind turbine systems. IEEE Trans Power Electron 2004;19(5):1242-9.

\section{Kratka biografija:}

Marko Stojanović je rođen je u Novom Sadu 1994. god. Završio gimnaziju Isidora Sekulić u Novom Sadu. Osnovne akademske studije i odbranu diplomskog rada završio na Fakultetu tehničkih nauka 2018. godine. Trenutno zaposlen u kompaniji Strabag.

Marko Vekić je vanredni profesor na Fakultetu tehničkih nauka u Novom Sadu, na Katedri za Energetsku elektroniku i pretvarače. Oblasti interesovanja su mu energetska elektronika u prenosnim i distributivnim mrežama, mikromreže i kvalitet električne energije. 